\title{
Analisa Penempatan Kamera CCTV Menggunakan Metode Simple Additive Weighting (SAW) Untuk Smart Monitoring
}

\author{
Gianto Widodo, Rahmadwati Purnomo Budi Santoso, Fachrul Kurniawan
}

\begin{abstract}
-monitoring technology is an area or region now is growing rapidly, this refers to the interest to be used. Closed Circuit Television (CCTV) is a type of camera that was used for the supervisor of the building or room, but it can also be used to monitor the condition of congestion and road conditions. The problems are the installation of CCTV is not always right on target because it is only installed for trend following, without looking at the conditions that will be installed, so it becomes less than optimal. Many of the problems in need of supervision by the Government. Problems such as road density, accidentprone area, business area, area schools, parking area and population density at the location of the road is a problem that requires supervision. In order for the supervision can be done with the optimal technological devices are used then the information and communication technology, the utilization for surveillance of a region commonly referred to with the Smart Monitoring, the device that can be used is CCTV. In order to target the right CCTV installation requires a calculation and analysis of the right against the conditions of the point to be fitted, to allow the installation of CCTV can be right on target and not just follow the trend of development of the technology. Many of the problems that have to be analyzed before the installation of CCTV, to find the solution of many problems, this research using methods MCDM method Simple Additive Weighting (SAW). Based on the results of the calculation of 40 data points of observation in the city of XYZ with 10 categories, problems and preferences 3 weights used produce a value $\mathrm{Vi}$ maximum 4 point, and that point is recommended for CCTV installed.
\end{abstract}

\section{Keywords: SAW, CCTV}

Abstrak - Teknologi monitoring sebuah area atau wilayah sekarang ini berkembang dengan cepat, hal ini mengacu pada kepentingan yang ingin digunakan. Closed Circuit

Manuscript received September 02, 2016. This work was supported in part by Electrical Engineering Department University of Brawijaya.

Gianto Widodo is the Electric Engineering Departement of Brawijaya University,

Indonesia.(email:wido_32@yahoo.com )

Rahmadwati is the Electric Engineering Departement of Brawijaya University, Malang, Indonesia. (email : rahma@ub.ac.id )

Purnomo Budi Santoso is the Industrial Engineering Departement of Brawijaya University, Malang, Indonesia. ( email : pbsabn@yahoo.com )

Fachrul Kurniawan is the Departement of Electric Engineering ITS, Surabaya, Indonesia.Departement of Informatic Engineering Islamic State University of Maulana Malik Ibrahim Malang ( email : fach_77@yahoo.com )
Television (CCTV) adalah jenis kamera yang biasa digunakan untuk pengawas gedung atau ruangan, tetapi bisa juga digunakan untuk memantau kondisi kemacetan dan keadaan jalan. Pemasalahannya adalah pemasangan CCTV tidak selalu tepat sasaran karena hanya dipasang untuk mengikuti trend, tanpa melihat kondisi tempat yang akan dipasang, sehingga menjadi kurang optimal.

Banyak permasalahan di jalan yang membutuhkan pengawasan oleh pemerintah. Permasalahan seperti kepadatan jalan, area rawan kecelakaan, area bisnis, area sekolah, area parkir liar dan kepadatan penduduk di lokasi jalan adalah permasalahan yang membutuhkan pengawasan. Agar pengawasan bisa dilakukan dengan optimal maka digunakan perangkat tekonologi informasi dan komunikasi, pemanfaatan teknologi untuk pengawasan terhadap suatu wilayah biasa disebut dengan Smart Monitoring, perangkat yang bisa digunakan adalah CCTV. Agar tepat sasaran pemasangan CCTV membutuhkan sebuah perhitungan dan analisa yang tepat terhadap kondisi titik yang akan dipasang, agar pemasangan CCTV bisa tepat sasaran dan tidak sekadar mengikuti trend perkembangan teknologi. Banyak permasalahan yang harus dianalisa sebelum pemasangan CCTV, untuk mencari solusi dari banyak permasalahan tersebut, penelitian ini menggunakan metode MCDM yaitu metode Simple Additive Weighting(SAW). Berdasarkan hasil perhitungan 40 data titik pengamatan di Kota XYZ dengan 10 kategori permasalahan dan 3 preferensi bobot yang digunakan menghasilkan nilai $\mathrm{Vi}$ maksimum sebanyak 4 titik, dan titik tersebut direkomendasikan untuk dipasang CCTV.

\section{Kata Kunci: SAW, CCTV}

\section{PENDAHULUAN}

Closed Circuit Television (CCTV) adalah teknologi yang digunakan untuk mempermudah melakukan pengawasan suatu wilayah. Bukan hanya untuk pengawas gedung atau ruangan, sekarang CCTV mulai digunakan untuk keperluan lain seperti memantau kondisi suatu jalan. Banyak permasalahan di jalan yang membutuhkan pengawasan oleh pemerintah. Menurut hasil analisa yang telah dilakukan, serta hasil tanya jawab dengan petugas lalu lintas Kota XYZ, ada beberapa permasalahan di jalan yang perlu mendapatkan perhatian. Permasalahan seperti kepadatan penduduk di area jalan, kepadatan lalu lintas, lokasi bisnis, area rawan kecelakaan, area sekolahan, persimpangan jalan, dan area parkir liar adalahpermasalahan yang perlu mendapatkan pengawasan yang tidak mungkin 
dilakukan, karena area yang luas, sehingga perlu memanfaatkan teknologi informasi modern, salah satu teknologi

yang bisa digunakan adalah CCTV, penggunaan teknologi ini disebut juga dengan Smart Monitoring.

Permasalahan yang muncul ketika menggunakan teknologi ini adalah banyaknya kriteria yang belum masuk dalam pertimbangan pemasangan CCTV, oleh karena itu dibutuhkan sebuah analisa yang tepat dalam penentuan titik distibusi penempatan CCTV secara tepat.

Sistem optimasi yang digunakan adalah pemilihan beberapa tindakan alternatif yang ada untuk mencapai satu atau beberapa tujuan yang telah ditetapkan. Sistem optimasi ini untuk membantu keputusan menentukan lokasi penampatan CCTV sesuai kriteria yang telah dirumuskan

Sistem optimasi keputusan merupakan sebuah solusi yang tepat ketika menghadapi permasalahan yang kompleks dan sulit untuk menemukan keputusan dari permasalahan yang dihadapi. Dengan menggunakan metode pencarian solusi dari banyak permasalahan yang dihadapi, Sistem optimasi bisa menghasilkan solusi yang lebih tepat. Salah satu metode optimasi keputusan dari banyak kriteria permasalahan atau Multi Criteria Decision Making(MCDM) adalah metode Simple Additive Weighting (SAW).

Penelitian terdahulu yang menggunakan metode SAW dalam pengembangan sistem optimasi keputusan adalah penerapan SAW untuk proses seleksi karyawan terbaik, sistem tersebut menggunakan 7 kriteria permasalahan dan digunakan untuk menyeleksi 5 karyawan, dan berhasil menentukan 1 karyawan terbaik $^{[1]}$.

Penelitian berikutnya tentang tinjauan penggunaan metode MCDM pada penelitian internasional yang menggunakan metode SAW selama 10 tahun terakhir disimpulkan bahwa metode SAW menempati posisi tertinggi dengan prosentase $52 \%$, hal ini menandakan jika metode SAW adalah metode yang cukup baik dan banyak dipercaya sebagai metode optimasi penentuan keputusan $^{[3]}$.

Tujuan dari penelitin ini adalah mengembangkan sebuah sistem optimasi keputusan dalam menentukan distribusi penempatan CCTV di kota XZY dengan metode SAW.

\section{DASAR TEORI}

1. Algoritma Simple Additive Weighting $(S A W)$

Algoritma SAW dikenal sebagai metode penjumlahan bobot dari rating kinerja pada setiap alternatif ${ }^{[4]}$. Metode SAW membutuhkan proses normalisasi matriks keputusan (X). Formula untuk melakukan normalisasi tersebut menggunakan persamaan 1 berikut ini:

$r_{i j}= \begin{cases}\frac{x_{i j}}{\operatorname{Max}_{i}} & j i k a \mathrm{j} \text { adalah atribut keuntungan (benefit) } \\ \frac{\operatorname{Min}_{i} x_{i j}}{x_{i j}} & \text { jika } \mathrm{j} \text { adalah atribut biay a (cost) }\end{cases}$

dengan:

xij : Kriteria berdasarkan posisi baris i dan kolom j

rij: Rating kinerja ternormalisasi dari alternatif $\mathrm{Ai}$ pada atribut $\mathrm{Cj} ; \mathrm{i}=1,2, \ldots, \mathrm{m}$ dan $\mathrm{j}=1,2, \ldots, \mathrm{n}$.

Untuk menentukan hasil, dilakukan perhitungan nilai preferensi setiap alternatif (Vi) dengan persamaan 2 berikut ini:

$$
V_{i}=\sum_{j=1}^{n} w_{j} r_{i j}
$$

dengan:

wj: Bobot kriteria sesuai dengan posisi kolom j

rij: Rating kinerja ternormalisasi dari alternatif $\mathrm{Ai}$ pada atribut $\mathrm{Cj} ; \mathrm{i}=1,2, \ldots, \mathrm{m}$ dan $\mathrm{j}=1,2, \ldots, \mathrm{n}$.

jika:Nilai Vi yang lebih besar mengindikasikan bahwa alternatif Ai memiliki prioritas tertinggi.

\section{TAHAP PENELITIAN}

Tahapan penelitian dimulai dari proses analisis dan pencarian data yang dibutuhkan, hingga penyusunan langkah-langkah algoritma SAW dalam penelitian.

1. Persiapan Data

Data yang didapatkan untuk penelitian ini adalah data sekunder dari kota XYZ dan hasil analisis dari beberapa data sekunder yang didapatkan dari sumber internet. Data yang digunakan sebagai variabel dalam penelitian ini adalah sebagai berikut:

a. Data kriteria

Data kriteria adalah data permasalahan yang akan dianalisa dengan menggunakan metode SAW. Penentuan kriteria pada penelitian ini berdasarkan hasil tanya jawab dengan petugas Dinas Perhubungan Kota XZY dan hasil analisa dari penelitian tentang permasalahan di jalan. Kriteria yang digunakan pada penelitian ini adalah data kepadatan penduduk di area jalan, kepadatan lalu lintas, lokasi bisnis, area rawan kecelakaan, area sekolahan, area kampus, persimpangan jalan, jarak titik pengamatan dengan pusat kontrol CCTV, kriteria jalan dan area parkir liar yang biasanya terjadi pada jalur angkutan umum. Data kriteria yang digunakan adalah permasalahan yang ada pada 159 ruas jalan di Kota XZY.

b. Data bobot

Data bobot adalah nilai bobot yang diberikan pada setiap permasalahan yang dijadikan kriteria. Data bobot didapatkan dari pakar dari dinas badan perencanaan daerah Kota XZY.

c. Data titik pengamatan

Data titik pengamatan merupakan data titik persimpangan yang didapatkan dari Dinas Perhubungan Kota XYZ, dimana data persimpangan tersebut merupakan titik pengamatan yang menjadi target tempat pemasangan CCTV. Berdasarkan data yang didapatkan dari Kota XZY Terdapat 40 titik pengamatan yang bisa dianalisa.

2. Prosedur Algoritma SAW

Data data yang telah didapatkan diproses menggunakan prosedur dalam metode SAW, adapun proses yang dilakukan adalah sebagai berikut:

1. Memasukkan data kriteria dan alternatif. 
2. Memasukkan nilai rating kecocokan pada setiap kriteria dari setiap titik pengamatan.

3. Melakukan pencarian nilai maksimal pada setiap kolom kriteria untuk kiteria benefit, dan mencari nilai minimal pada kriteria cost dengan menggunakan persamaan 1 .

4. Membagi nilai setiap kriteria dengan nilai maksimal hasil perhitungan tahap 3 untuk kriteria benefit, dan membagi nilai minimal hasil perhitungan tahap 3 dengan nilai kriteria untuk kriteria cost.

5. Menyusun kembali hasil bagi pada tahap 4 untuk mendapatkan matriks ternormalisasi R.

6. Dilakukan proses pembobotan menggunakan persamaan 2. Bobot yang digunakan adalah preferensi bobot dari dinas badan perencanaan daerah Kota XZY.

7. Dilakukan proses perangkingan untuk menghasilkan rekomendasi pemasangan CCTV.

\section{IMPLEMENTASI DAN ANALISA HASIL}

Dari 40 data titik pengamatan yang telah didapakan, dianalisa dengan tahapan yang nampak pada Gambar 1 berikut ini:

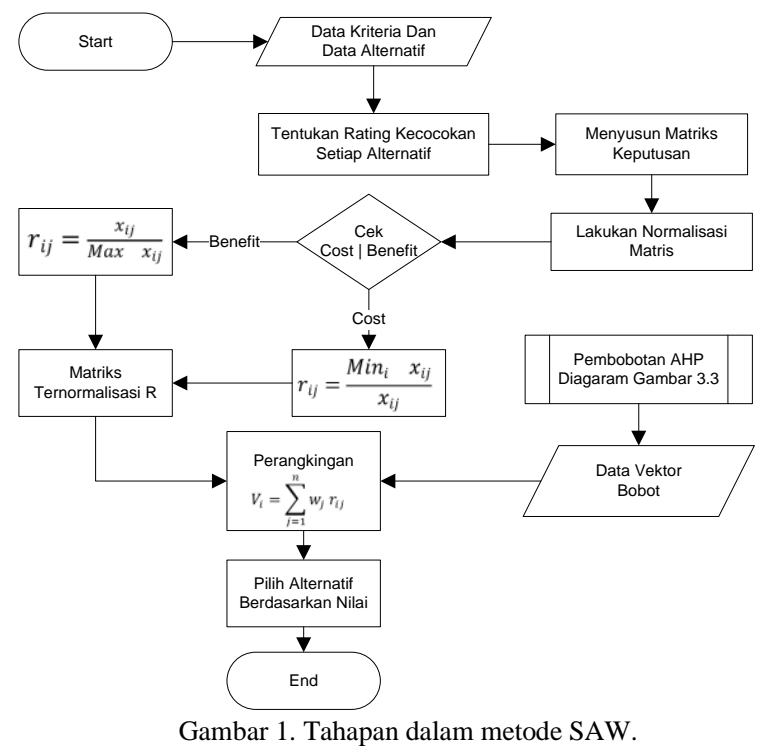

Tahapan yang nampak pada Gambar 1 menjelaskan proses algoritma SAW dalam menghitung nilai kriteria untuk menghasilkan nilai Vi. Nilai Vi merupakan nilai yang dihasilkan dari proses algoritma SAW, dimana nilai tersebut berasal dari perhitungan kriteria-kriteria yang telah ditentukan tiap titik pengamatan.

Data kriteria yang digunakan dalam proses perhitungan nampak pada Tabel 1 berikut ini:

Tabel 1. Data Kriteria

\begin{tabular}{ll}
\hline Kriteria (C) & Nama Kriteria \\
\hline C1 & Kepadatan Penduduk \\
C2 & Kepadatan Jalan \\
C3 & Kriteria Jalan \\
C4 & Jumlah Perguruan Tinggi \\
C5 & Area Bisnis \\
C6 & Kejadian Laka Lantas \\
C7 & Jenis Persimpangan \\
\end{tabular}

\begin{tabular}{ll}
\hline Kriteria (C) & Nama Kriteria \\
C8 & Jalur Angkot \\
C9 & Jarak Lokasi \\
C10 & Jumlah Sekolahan \\
\hline
\end{tabular}

Kriteria yang ada pada Tabel 1 didapatkan dari pakar dan juga hasil analisa dari beberapa penelitian sebelumnya dari pemerintah Kota XYZ.

Kriteria-kriteria tersebut diproses menggunakan preferensi bobot dari pakar. Bobot untuk proses perhitungan yang didapatkan dari pakar di Kota XZY seperti Tabel 2 berikut ini:

Tabel 2. Preferensi bobot

\begin{tabular}{llllllllll}
\hline C1 & C2 & C3 & C4 & C5 & C6 & C7 & C8 & C9 & C10 \\
\hline 9 & 8 & 8 & 8 & 8 & 7 & 7 & 5 & 5 & 9 \\
\hline
\end{tabular}

Perhitungan dilakukan pada 40 titik pengamatan, yaitu data persimpangan yang didapatkan dari pemerintah Kota XZY,

Dengan menggunakan data kriteria, bobot dan titik pengamatan tersebut kemudian dilakukan proses peniliaian dan didapatkan hasil normalisasi matriks(X). Kemudian dilakukan proses perangkingan nilai Vi. Data pada tabel 3 berikut ini memperlihatkan 8 titik hasil perangkingan yang telah dilakukan.

Tabel 3. Hasil perangkingan nilai Vi.

\begin{tabular}{lll}
\hline No & Nama titik pengamatan & Nilai Vi \\
\hline $\mathbf{1}$ & Raden Intan & 0.68237 \\
$\mathbf{2}$ & Panjaitan-Suhat & 0.64468 \\
$\mathbf{3}$ & Dinoyo & 0.64138 \\
$\mathbf{4}$ & Blimbing & 0.62655 \\
$\mathbf{5}$ & Borobudur & 0.59756 \\
$\mathbf{6}$ & Gadang & 0.59719 \\
$\mathbf{7}$ & Kota Lama & 0.5663 \\
$\mathbf{8}$ & Soehat & 0.54773 \\
\hline
\end{tabular}

Setelah dilakukan proses perangkingan nilai Vi, kemudian dilanjutkan proses klasifikasi untuk memudahkan pengelompokan hasil, sehingga akan didapatkan jumlah jalan yang terdapat dimasing-masing klasifikasi. Range nilai untuk klasifikasi terdapat pada Tabel 4.

Tabel 4. Interval klasifikasi nilai Vi

\begin{tabular}{lll}
\hline No & Nama Klasifikasi & Nilai Interval \\
\hline $\mathbf{1}$ & Klasifikasi 4 & $0.34190-0.375947$ \\
$\mathbf{2}$ & Klasifikasi 3 & $0.375948-0.444041$ \\
$\mathbf{3}$ & Klasifikasi 2 & $0.444042-0.546182$ \\
$\mathbf{4}$ & Klasifikasi 1 & $0.546183-0.68237$ \\
\hline
\end{tabular}

Dari 40 data titik yang diamati Nilai Vi yang masuk dalam kelas klasifikasi 1 sebanyak 2 titik, klasifikasi ke 2 sebanyak 7 titik kemudian klasifikasi ke 3 sebanyak 23 titik dan yang terakhir klasifikasi ke 1 yang mempunyai interval terbesar sebanyak 8 titik. Jumlah titik setiap klasifikasi yang telah disebutkan nampak pada grafik yang ada pada Gambar 2 berikut ini: 


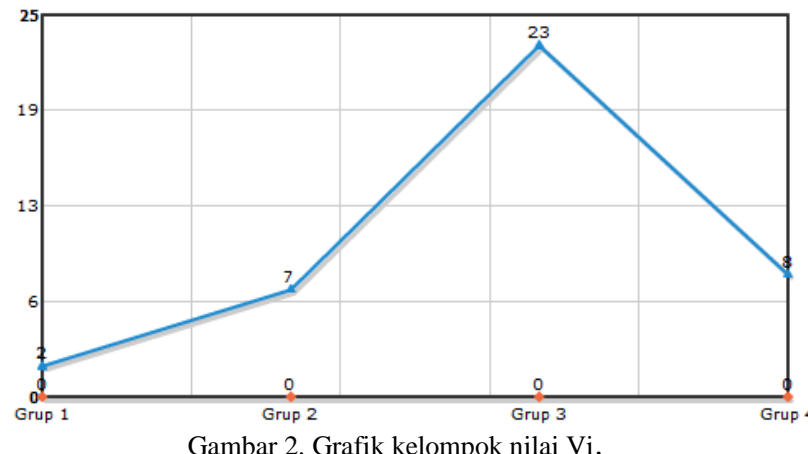

Berdasarkan pengelompokan tersebut interval terbesar yaitu interval ke 4 dijadikan acuan dalam menentukan rekomendasi titik penempatan CCTV, oleh karena itu hasil penelitian ini merekomendasikan 8 titik pengamatan utama yang direkomendasikan yaitu raden intan dengan nilai Vi 0.68237, panjaitan-suhat nilai Vi 0.64468 , dinoyo nilai Vi 0.64138 , Blimbing nilai Vi 0.62655 , Borobudur nilai Vi 0.59756, Gadang nilai Vi 0.59719 , Kota Lama nilai Vi 0.5663 dan yang terakhir Soehat dengan nilai Vi 0.54773.

\section{KESIMPULAN}

Berdasarkan data hasil yang telah dianalisa maka dapat ditarik kesimpulan:

1. Distribusi penaatn CCTV untuk Smart Monitoring bisa menggunakan algoritma SAW sebagai metode dalam mengoptimalkan penentuan titik pemasangan CCTV.

2. Hasil perhitungan merekomendasikan 4 klasifikasi titik penempatan yang dibedakan berdasarkan nilai Vi.

3. Untuk lebih mengoptimalkan hasil penelitian ini maka akan dilanjutkan penelitian menggunakan metode SAW-AHP dan WP.

\section{DAFTAR PUSTAKA}

[1] Alireza Afshari, M. M. (2010). Simple Additive Weighting approach to Personnel Selection problem. International Journal of Innovation, Management and Technology, Vol. 1, No. 5.

[2] Kurdi, H. A. (2014). Review of Closed Circuit Televisison (CCTV) Techniques for Vehicles Traffic Management. International Journal of Computer Science \& Information Technology (IJSIT) Vol.6 , No.2.

[3] Lazim Abdullah, C. R. (2014). Simple Additive Weighting Methods of Multi criteria Decision Making and Applications: A Decade Review. International Journal of Information Processing and Management(IJIPM), 39-49.

[4]Turban, E. A. (2005). Decision Support System and Intelligent Systems. New Delhi: Asoke K. Ghosh, Prentice-Hall of India Private Limited. 